\title{
FLUX DEVIATING TECHNIQUE TO ENHANCE THE TOTAL MAGNETIC FLUX DENSITY IN THE FLUID FLOW GAP OF A MONOTUBE SINGLE COIL MR DAMPER
}

\author{
GANESHA. A \& A. AMAR MURTHY* \\ Department of Mechanical and Manufacturing Engineering, Manipal Institute of Technology, \\ Manipal Academy of Higher Education, Manipal, India
}

\begin{abstract}
Magneto-Rheological (MR) fluids having the magnetic field dependent viscosity is responsible for the variable damping coefficient of MR dampers. The energy dissipated by the MR damper has a direct influence of the total magnetic flux density in the fluid flow gap. The total magnetic flux density is a function of geometric, material property and operating condition. In this paper, the flux deviating technique in the form of diamagnetictic coating is incorporated in the damper to enhance the total magnetic flux density in the fluid flow gap. The magnetostatic analysis is used to compute the magnetic flux density in the fluid flow gap of three different monotube single coil MR damper models. A significant increase in the flux density is observed in a model having a continuous diamagnetic coating. Further, a reduction in the flux density is observed for a damper model having a discontinuous coating.
\end{abstract}

KEYWORDS: Magnetostatic Analysis, MR Damper, Monotube, Diamagnetic \& Flux Deviating Technique

Received: Mar 22, 2019; Accepted: Apr 13, 2019; Published: May 13, 2019; Paper Id.: IJMPERDJUN201983

\section{INTRODUCTION}

A recent encouraging development in the vehicle suspension design is the use of Magneto-Rheological (MR) fluids in the dampers. The magnetic field dependent viscosity of the MR fluid changes significantly (105-106 times within milliseconds) when the magnetic field is applied. This effect is completely reversible when the magnetic field is removed[1]. The damping coefficient of MR damper is varied by changing the magnetic flux. In MR damper, the damping force is highly influenced by the magnetic flux density in the fluid flow gap. The development in the computation techniques has given tremendous support in maximizing the damping force of an MR damper by varying the influencing parameters.

Krishna et al. analytically studied the magnetic flux distribution in the fluid flow gap of a twin tube MR damper.[2], and a new statistical segregation approach is proposed to calculate the damping force using flux density. This method was experimentally validated by Krishna et al.[3]. Different parameters influence the flux distribution pattern in the MR damper. Finite element analysis and genetic algorithm based optimization technique are explained by Krishna et al. [4]. This study highlighted the dominance of dimensions of fluid flow gap. The computational timing in the finite element analysis can be reduced by proper utilization of the geometric symmetry properties. An axis symmetric model of MR damper was studied by Chao et al., [6], using ANSYS package and a fourth order polynomial relationship between the magnetic flux density and the shear stress was established. PLANE 13 element in ANSYS package has the capability of 2D magnetic, piezo electric and structural modeling. 
A modeling technique of MR damper having two-stage coil by using a PLANE 13 element and the effect of magnetic saturation on the maximum damping force was explained by Zhang, H. H et al., [7]. MR fluids can be operated in valve mode squeeze mode and direct shear mode. Generally, the MR dampers operate in direct shear mode. A hybrid MR damper was designed by Yazid et al.[8], which has a combination of shear and squeeze mode. The magnetic field around this damper was simulated by using FEA technique. The fluid dynamic of MR fluid involves the coupling of the magnetic field in the flow equation. A multi-physics behavior of three coil MR damper was investigated by A. Sternberg, R. Zemp and J.de la Llera.[10]. In this investigation, the magnetic flux is evaluated through magnetostatic analysis. Parlak, Zekeriya, and Tahsin Engin. [11], computationally investigated the flow characteristics of MR fluid in the fluid flow gap of an MR damper by treating the fluid flow gap as the non-Newtonian region. In this investigation, damper force was calculated by using the quasi-static model, and the transient deformed mesh technique was used in the analysis. The performance of MR damper depends on the geometric parameters and operating parameters. The optimum influencing geometric parameter and volume fraction of MR fluid for damper application were investigated by Gurubasavaraju et al. [12]. This investigation, through ANOVA, proved that a fluid flow gap and operating current has a significant effect on the damping force. The influence of properties of piston material on the damping force of an MR damper was analytically studied by Gurubasavaraju et al. [13][14]. Considering three models made of SA1020, SST 430 and M36 materials, it revealed that there is a significant effect of piston materials on the damping force.

In the recent past years, many researchers analyzed and optimized the model specific MR damper. Majority of the researchers achieved the maximum flux density near the entry and exit of the fluid flow gap. There is a large volume of fluid in the flow gap exposed to lower value of magnetic flux density. Hence there is wide scope to maximize the flux density in the fluid flow gap. This paper presents the flux deviating technique to maximize the magnetic flux density in the flow gap.

\section{METHODOLOGY}

The flux deviating technique is based on the concept of flux line direction in Ferromagnetic, diamagnetic and paramagnetic materials. A diamagnetic material deflects the flux lines when it is placed in the magnetic field. In this investigation, a monotube single coil MR damper having a piston of diameter $30 \mathrm{~mm}$ and cylinder of diameter $32 \mathrm{~mm}$ is considered as the reference model[13]. The schematic representation of the base model is shown in Figure 1. The flux density in the fluid flow gap of the base model is compared with the same obtained from an MR damper having continuous and discontinuous diamagnetic coatings at the outer wall of the cylinder. The thickness of the continuous coating is selected as 0.25 times fluid flow gap. In discontinuous coating 0.3 times, the fluid flow gap is selected as the length of the coating along the axis of the cylinder from the upper and lower face of the piston, and the same thickness as that of the continuous coating is maintained. The coil of the MR damper has 700 turns, and a direct current of 1 amp is applied from 9 $\mathrm{V}$ supply. The flux density in the fluid flow gap is calculated by using magnetostatic analysis module in ANSYS workbench 18. Maxwell's equation(1-3) are solved for magneto static analysis[15]

$$
\begin{aligned}
& \nabla \times H=J \\
& \nabla \cdot B=0 \\
& \mathrm{~B}=\mu_{0} \mu_{r}(H) \cdot H
\end{aligned}
$$

Where 
$\nabla \quad$ Denotes divergence

$\mathrm{H} \quad$ is the magnetic field density

$\mathrm{J} \quad$ is the current density

B is the magnetic flux density

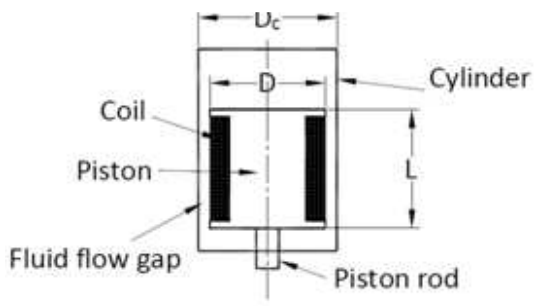

$\mathrm{D}_{\mathrm{c}}$ Diameter of the cylinder

D Diameter of the Piston

L Length of the Piston

Figure 1: Schematic Representation of the Base Model

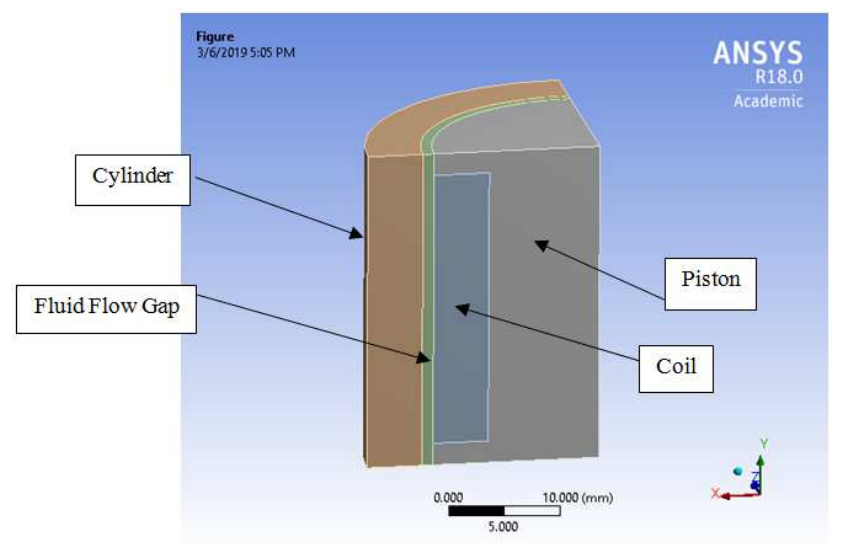

(a)

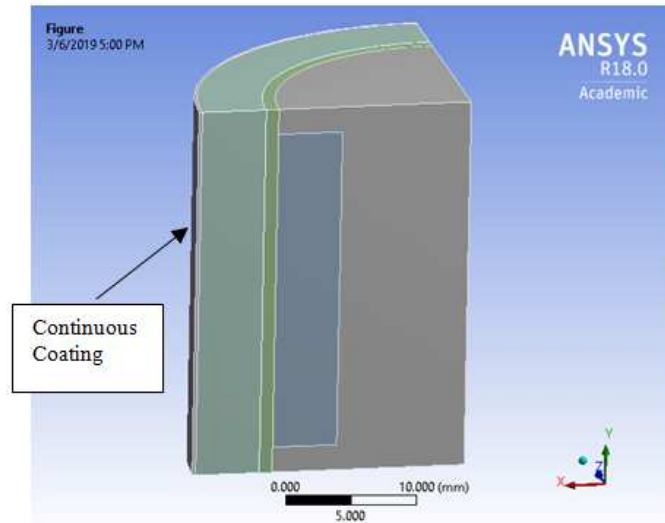

(b)

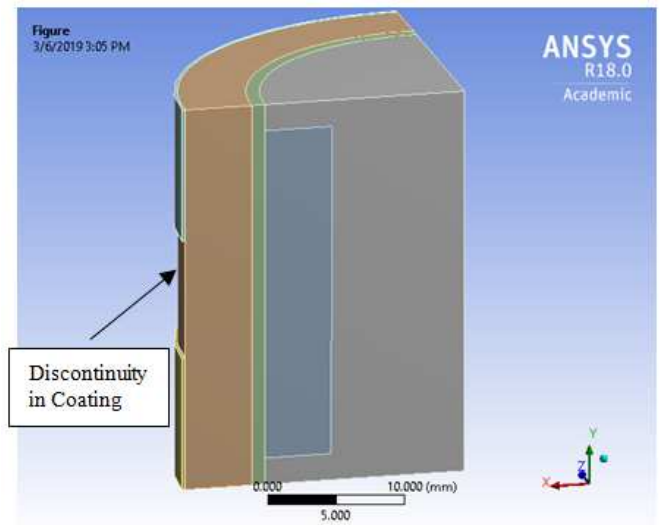

(c)

Figure 2: Computational Domain (a) Without Coating

(b) Continuous Coating (c) Discontinuous Coating

The geometric models of three damper models are shown in figure 2 . The first model is not having any coating and is considered a base model. The Second model has the continuous diamagnetic coating on the outside wall of the cylinder as shown in figure 2(b). In the third model, a coating material discontinuity is introduced at the center of the cylinder as shown in figure 2(c). The methodology of this investigation is shown in figure 3. 


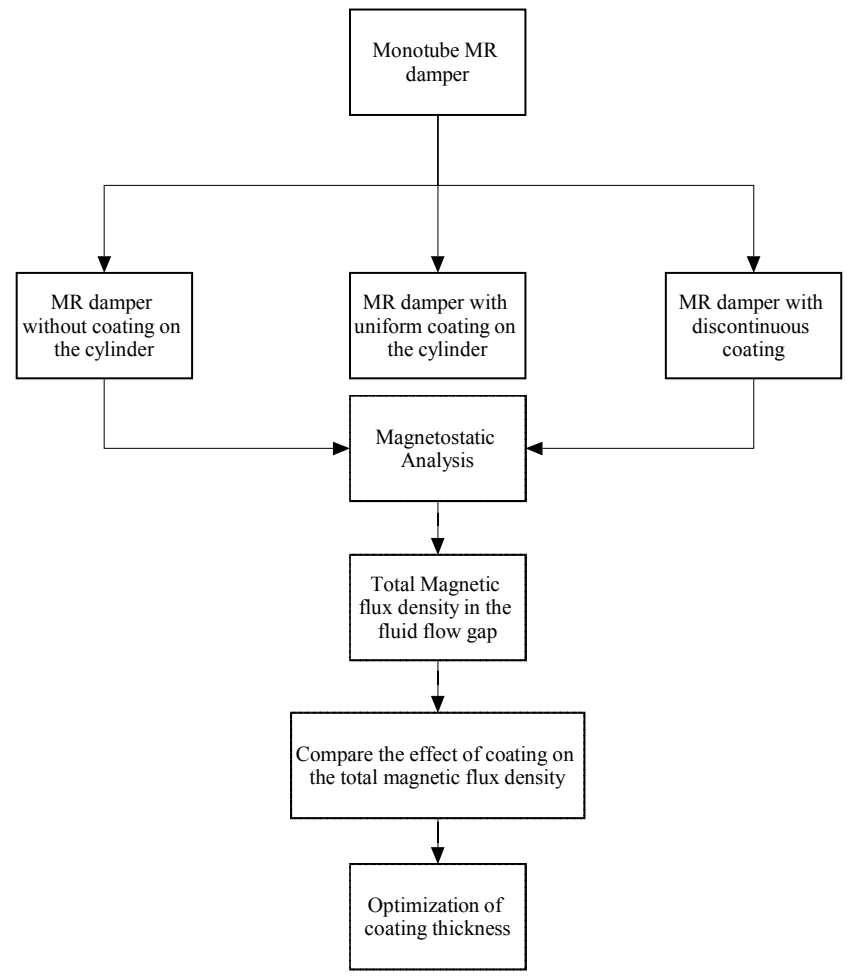

Figure 3: Methodology Flow Chart

The MR damper is symmetric about two principal planes. This feature gives provision to consider only onequarter of the damper as the computational domain, thereby reduces the computational effort. SOLID117 element is used to mesh the geometry of the damper. A structured mesh is obtained in the fluid flow gap with 2800 elements. In the boundary conditions, the flux lines are assumed to be parallel about the symmetric planes. The material properties of different parts of the MR dampers are shown in table 1. The B-H curves of MR fluid and Piston Material are shown in figure 4 .

Table 1: Material Properties of Different Parts of MR Damper

\begin{tabular}{|c|l|l|c|}
\hline Sl. No & Part Name & \multicolumn{1}{|c|}{ Material } & Relative Permeability \\
\hline 1 & Piston & SA1020 & B-H curve \\
\hline 2 & Coil & Copper wire & 1 \\
\hline 3 & Cylinder & Stainless Steel & 2000 \\
\hline 4 & Coating & Copper & 0.999994 \\
\hline
\end{tabular}

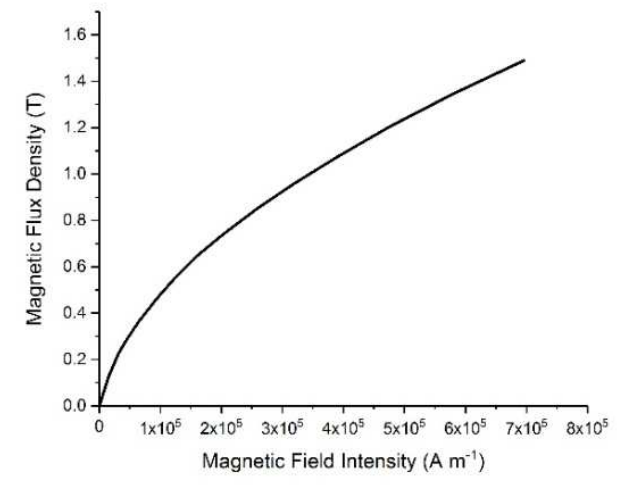

(a)

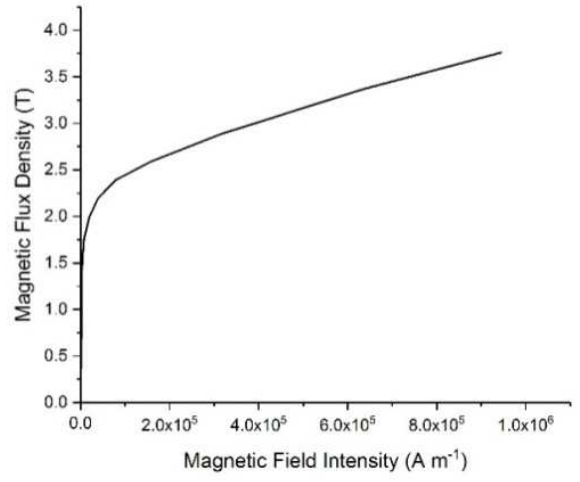

(b)

Figure 4: B-H Curve of (a) MRF-132DG (Lord Co.)[16]. (b) S1020 


\section{RESULTS AND DISCUSSIONS}

The total magnetic flux density in the fluid flow gap for the three models are shown in figure 5. The highest total magnetic flux density of $885.97 \mathrm{mT}$ is obtained in the fluid flow gap for the damper having a continuous diamagnetic coating. Also in this model, a significant improvement of minimum total magnetic flux density in the fluid flow gap is observed. This is because of the deviation flux lines in the damper body. The discontinuous coating on the cylinder resulted in a decrease in the highest total magnetic flux density. The magnitude of this flux density (842.69 mT) is significantly lesser than that obtained for the damper model without having any coatings.

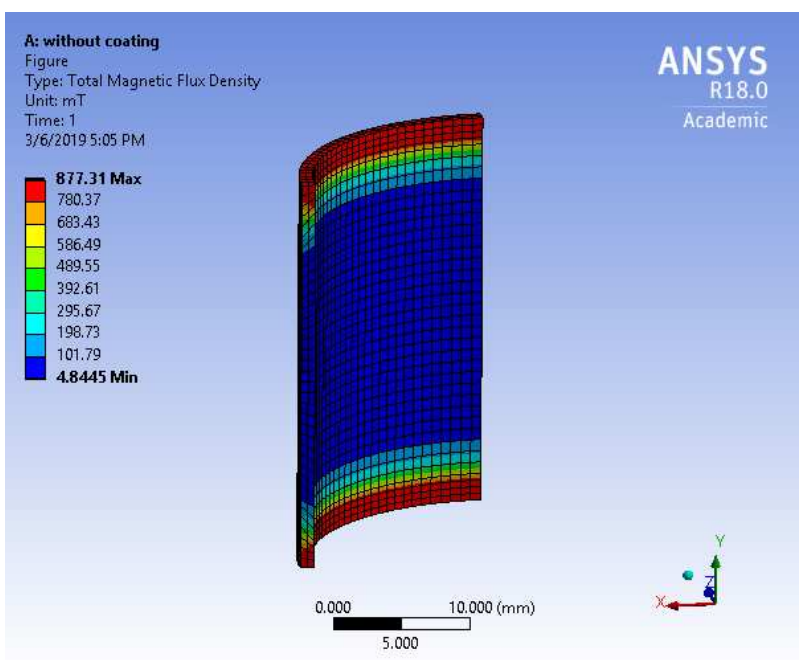

(a)

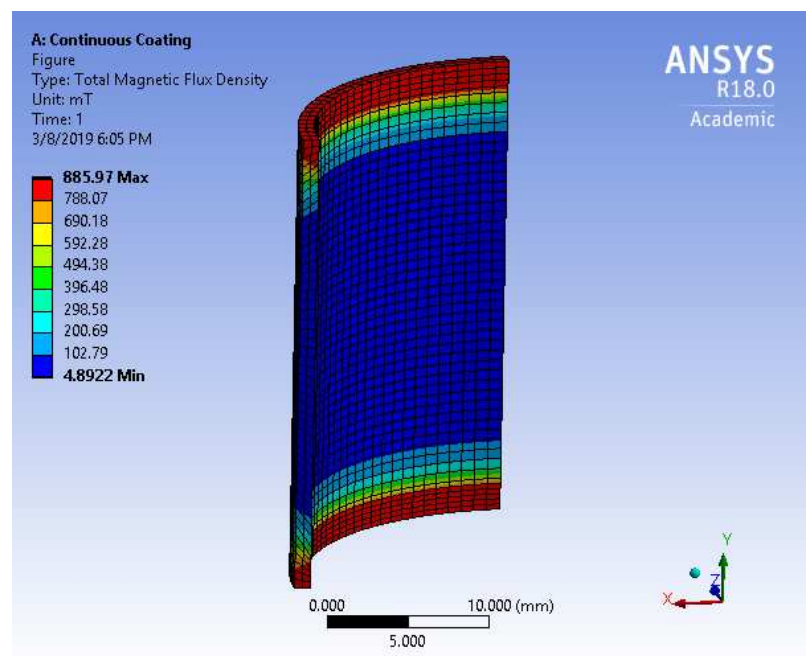

(b)

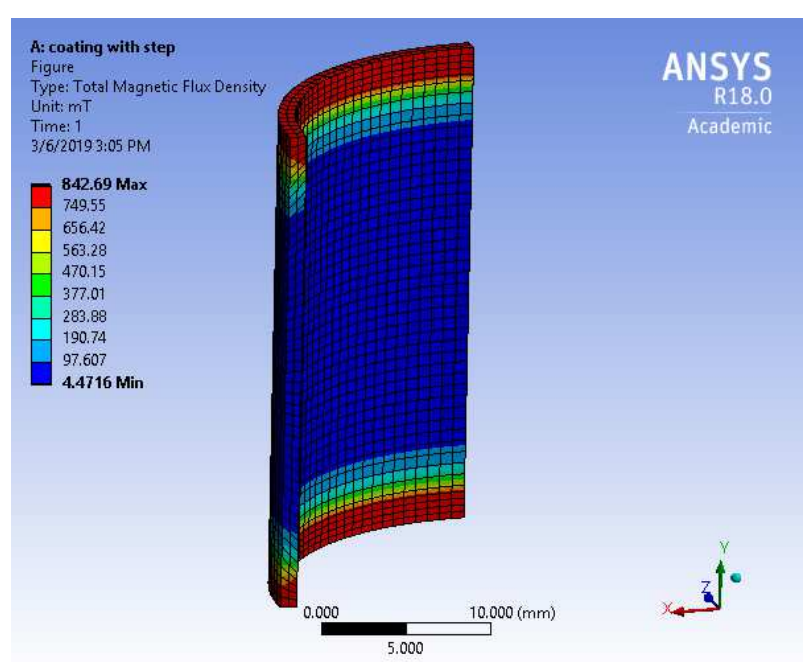

(c)

Figure 5: Total Magnetic Flux Density in the Fluid Flow Gap (a) Without Coating (b) Continuous Coating

(c) Discontinuous Coating 

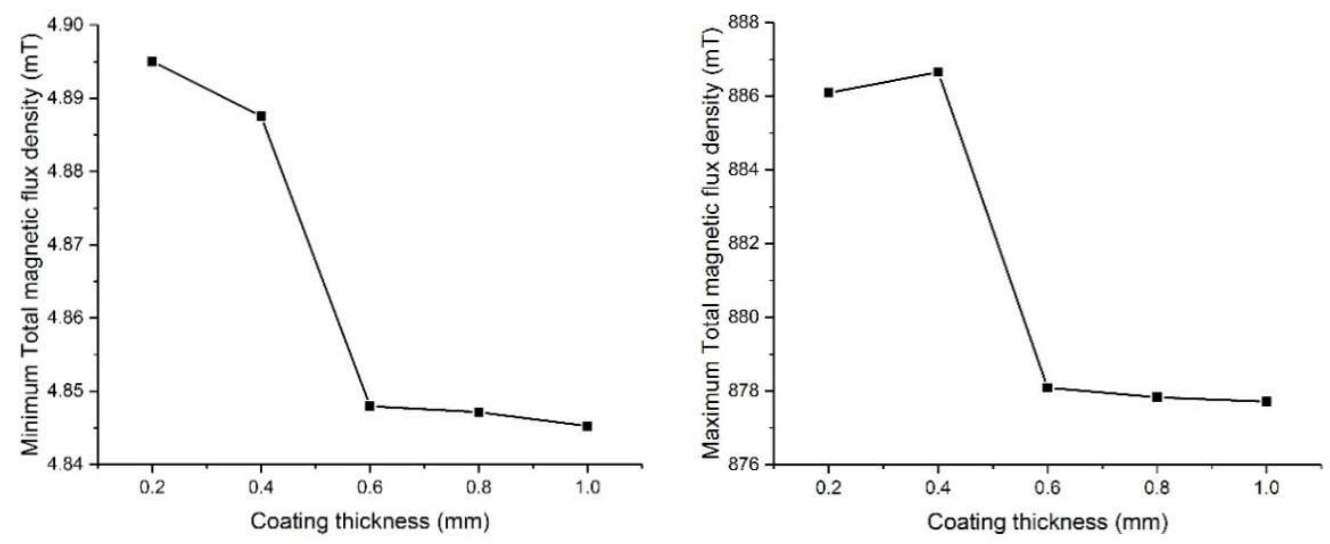

Figure 6: Effect of Full Coating Thickness on the Total Magnetic Flux Density in the Fluid Flow Gap

The continuous coating on the cylinder gives the highest flux density in the fluid flow gap. Hence the effect of coating thickness is investigated for five different thicknesses ranging from $0.2 \mathrm{~mm}$ to $1 \mathrm{~mm}$. The response of minimum total magnetic flux density and maximum total magnetic flux density is shown in figure 6 . The increase in coating thickness results in a decrease of minimum and maximum total magnetic flux density, but these values are higher than that obtained for the damper without coating.

\section{CONCLUSIONS}

In the present work, the influence of diamagnetic coating on the outer surface of the monotube single coil MR damper was investigated through computational methods. Three different models were considered for investigation. The model having continuous diamagnetic coating has shown the highest total magnetic flux density in the fluid flow gap. Further, the effect of coating thickness on total magnetic flux density is investigated. The results showed that the increase in coating thickness has negative effect on the total magnetic flux density in the fluid flow gap.

\section{REFERENCES}

1. S. Elizabeth Premalatha, R. Chokkalingam, and M. Mahendran, "Magneto Mechanical Properties of Iron Based MR Fluids," Am. J. Polym. Sci., vol. 2, no. 4, pp. 50-55, 2012.

2. K. Hemanth, A. Ganesha, K. Hemantha, and K. V. Gangadharan, Analysis of MR damper based on finite element approach, vol. 592-594. 2014.

3. K. Hemanth, H. Kumar, and K. V. Gangadharan, "Vertical dynamic analysis of a quarter car suspension system with MR damper,” J. Brazilian Soc. Mech. Sci. Eng., vol. 39, no. 1, pp. 41-51, 2017.

4. H. Krishna, H. Kumar, and K. Gangadharan, "Optimization of Magneto-Rheological Damper for Maximizing Magnetic Flux Density in the Fluid Flow Gap Through FEA and GA Approaches,” J. Inst. Eng. Ser. C, vol. 98, no. 4, pp. 533-539, 2017.

5. Duhan, R., \& Choudhary, S. (2014). Effect of different fluxes on hardness and microstructure of SS 304 in GTAW welding. International Journal of Mechanical Engineering, 3(4), 1-8.

6. Z. D. Chao, F. Tyan, S. H. Tu, and W. S. Jeng, "Finite Element Analysis of a Magnetorheological Fluid Damper," in The Canadian Society for Mechanical Engineering, 2015, no. November 2007, pp. 3145-3149.

7. H. H. Zhang, C. R. Liao, W. M. Chen, and S. L. Huang, "A magnetic design method of MR fluid dampers and FEM analysis on magnetic saturation," J. Intell. Mater. Syst. Struct., vol. 17, no. 8-9, pp. 813-818, 2006. 
8. I. I. M. Yazid, S. A. Mazlan, T. Kikuchi, H. Zamzuri, and F. Imaduddin, "Design of magnetorheological damper with a combination of shear and squeeze modes,” Mater. Des., vol. 54, pp. 87-95, 2014.

9. Mathew, L., \& Prabha, C. (2014). Effect of fluid viscous dampers in multi-storeyed buildings. Int. J. Res. Eng. Technol.(IMPACT: IJRET), 2, 59-64.

10. A. Sternberg, R. Zemp, and J. C. de la Llera, "Multiphysics behavior of a magneto-rheological damper and experimental validation," Eng. Struct., vol. 69, pp. 194-205, 2014.

11. Z. Parlak and T. Engin, "Time-dependent CFD and quasi-static analysis of magnetorheological fluid dampers with experimental validation,” Int. J. Mech. Sci., vol. 64, no. 1, pp. 22-31, 2012.

12. T. M. Gurubasavaraju, H. Kumar, and M. Arun, "Evaluation of optimal parameters of MR fluids for damper application using particle swarm and response surface optimisation,” J. Brazilian Soc. Mech. Sci. Eng., vol. 39, no. 9, pp. 3683-3694, 2017.

13. T. M. Gurubasavaraju, K. Hemantha, and M. Arun, "A study of influence of material properties on magnetic flux density induced in magneto rheological damper through finite element analysis,” MATEC Web Conf., vol. 144, p. 02004, 2018.

14. T. M. Gurubasavaraju, H. Kumar, and M. Arun, "Optimisation of monotube magnetorheological damper under shear mode," J. Brazilian Soc. Mech. Sci. Eng., vol. 39, no. 6, pp. 2225-2240, 2017.

15. J. Wallace, “ANSYS AIM Tutorial 3-D Magnetostatic Force Computation,” 2017.

16. mar-lord-mr." [Online]. Available:www.lordmrstore.com/_literature_231215/Data_Sheet_-_MRF-132DG_MagnetoRheological_Fluid.[Accessed: 08-Mar-2019]. 
